\title{
Compreendendo norma linguística para desatar outros nós
}

\author{
FARACO, Carlos Alberto; ZILLES, Ana Maria. Para conhecer norma \\ linguística. São Paulo: Contexto, 2017.
}

\author{
Clézio Roberto Gonçalves ${ }^{1}$ \\ Mariana Mendes Correa da Costa ${ }^{2}$ \\ Valter de Carvalho Dias ${ }^{3}$
}

O livro Para Conhecer Norma Linguística, de autoria de Carlos Alberto Faraco e Ana Maria Zilles, publicado pela Editora Contexto, em 2017, traz em suas 219 páginas os principais questionamentos sobre ideia de norma, sobretudo na Língua Portuguesa, fazendo com que seus leitores compreendam o seu conceito em diferentes contextos, contribuindo para o ensino de uma língua que respeite, acima de tudo, as variedades.

Carlos Alberto Faraco é professor (aposentado) titular da Universidade Federal do Paraná. Possui experiência na área de Linguística com ênfase em Linguística Aplicada; seus livros e artigos muito têm contribuído para uma discussão sistemática sobre língua. Publicou vários livros, dentre os quais destaca-se Norma culta brasileira: desatando alguns nós.

Ana Maria Zilles é professora titular de Linguística da Universidade do Vale do Rio dos Sinos. Dedica-se atualmente a estudos da variação e mudança linguística, como também políticas linguísticas, aquisição da linguagem, dentre outros. Em cooperação com Faraco, publicou Pedagogia da variação linguística: língua, diversidade e ensino, importante obra que discute a língua, especialmente no contexto escolar.

O livro ora comentado, além de uma breve apresentação, está organizado em quatro capítulos, a saber: (i) Norma: tecendo conceitos; (2) Norma: descrição e prescrição; (3) Breve histórico da normatização do português; e (4) Norma e ensino. Destaca-se ainda o caráter pedagógico da obra, ao disponibilizar, no final de cada capítulo, leituras complementares e questões a serem respondidas.

Na Apresentação, os autores deixam claro que não é fácil compreender o conceito de norma nos estudos linguísticos, evidenciando dois conceitos que precisam ser bem entendidos ao longo da

\footnotetext{
${ }^{1}$ Doutor em Semiótica e Linguística Geral pela Universidade de São Paulo; Professor Associado da Universidade Federal de Ouro Preto, pósdoutorando na Universidade Federal da Bahia. E-mail: cleziorob@gmail.com.

2 Mestranda em Letras: Estudos da Linguagem pela Universidade Federal de Ouro Preto. E-mail: marimendescorrea@gmail.com

${ }^{3}$ Doutor em Língua e Cultura pela Universidade Federal da Bahia; professor do Instituto Federal da Bahia. E-mail: vcarvalho@ifba.edu.br.
} 
leitura: o de norma normal que se refere ao o que se diz e o de norma normativa que diz respeito a $o$ como se deve dizer.

O primeiro capítulo desenvolve melhor os conceitos mencionados na apresentação de norma normal e de norma normativa. A primeira diz respeito ao conjunto de traços linguísticos de uma determinada comunidade de fala, as quais estão atreladas também ao espaço (sócio)geográfico que os falantes ocupam, pois, o falar varia de região para região. Variam também de acordo com o acesso aos bens culturais e à cultura letrada. Mesmo as normas normais utilizadas pelos falantes respeitam algumas regras, uma vez que os falantes tendem a ajustar a sua fala aos diversos contextos de uso.

Já a segunda, é considerada como a "(...) tentativa de regulamentar, controlar, normatizar o comportamento linguístico dos falantes em determinados contextos" (p. 12), remetendo-se ao que se entende como uma língua ideal, que cumpre com as normas e o seu "bom" uso.

Ao falar sobre essa segunda norma, os autores explicam a diferença entre norma culta e normapadrão. A primeira se refere às normas utilizadas por um grupo de falantes que se denominam cultos. A segunda é a mencionada norma normativa. Eles ressaltam ainda que a realidade linguística brasileira é dividida em variedades cultas/prestigiadas e variedades populares/estigmatizadas.

Retomando o conceito de comunidades de fala, Faraco e Zilles afirmam que não estão completamente isoladas na sociedade e inerentes aos processos de mudanças linguísticas, uma vez que as normas não são consideradas imutáveis, elas realizam trocas com outras comunidades, seja por meio da televisão, rádio, internet etc. É por meio desses contatos entre diferentes comunidades que a mudança linguística vai acontecendo.

Os autores reforçam que os linguistas precisam se debruçar sobre outras áreas de conhecimento, pois somente um trabalho multidisciplinar pode esclarecer os conceitos e definições que permeiam a língua, uma vez que os fatores linguísticos por si só não são capazes de definir a complexidade que a envolve, uma vez que ela também é um aglomerado de processos históricos, culturais e políticos.

Ainda nessa perspectiva, os autores mencionam os linguistas britânicos Michael Halliday, Angus McIntosh e Peter Strevens por tratarem também da heterogeneidade da língua, cujas variedades podem ser agrupadas em dialetos e registros.

Pela fala é possível identificar a qual comunidade linguística o falante pertence. Assim é possível recorrer ao conceito de comunidade de prática, que são os grupos sociais com os quais as pessoas se identificam e participam: futebol, família, escola etc. Dessa maneira, não há dialetos e registros estáticos, retomando a ideia de que todo falante é um camaleão linguístico.

Toda e qualquer variedade de uma língua, segundo Faraco e Zilles, possui plenitude formal, "(...) tem organização estrutural" (p. 45), ou seja, possui sua própria gramática. As variedades também possuem um potencial semiótico "(...) qualquer variedade está, em princípio, apta a atender as necessidades cognitivas, expressivas e comunicacionais de seus falantes" (p. 48). Justamente por isso, os autores reforçam que não há motivos para se hierarquizar uma língua, uma vez que tal hierarquização acontece socialmente devido aos grupos que a impõem ocuparem as posições de maior prestígio, estigmatizando, portanto, os falantes desprestigiados, e não propriamente sua variedade linguística.

Ao mesmo tempo em que tentam legitimar a língua, esses grupos discriminam aquelas que são diferentes das suas. Para os autores, uma solução possível para que tal ocorrência tivesse fim seria a 
democratização do acesso ao patrimônio da cultura escrita; enfatizando que nem tudo pode ou deve ser padronizado.

Para fechar o capítulo, os autores reforçam que nada na língua é estático e que essa está em constante mudança.

No capítulo dois, os autores principiam dizendo que há uma separação entre atitude descritiva e atitude normativa. A primeira é vista como parte essencial das atividades científicas, procurando explicar os fatos tais como realmente são. Enquanto a segunda é uma reação à heterogeneidade linguística, visando uma homogeneização.

Para a Linguística, todo fato que ocorre na língua deve ser estudado e valorizado. Os autores enfatizam em diversos trechos que os linguistas não são contra as normas linguísticas, apenas criticam as normas que são artificiais e impostas por uma suposta "língua correta", questionando as regras que não tem relação com a realidade linguística.

Neste capítulo, os autores definem ainda as funções de filólogos, gramáticos e linguistas, diferenciando-os quanto aos seus respectivos objetos de estudo. Assim, a função dos filólogos está "(...) vinculada à importância e ao prestígio que a escrita e os textos escritos - em especial os textos canônicos (religiosos ou artísticos) - foram adquirindo na vida das sociedades humanas" (p. 85).

A função dos gramáticos surgiu do trabalho elaborado por esses filólogos, uma vez que precisaram "(...) descrever e comentar a língua (...)" (p. 87) que encontravam nos textos, ou seja, as regras que diziam respeito aos aspectos de métrica, ortografia, classificação das palavras, organização das orações, dentre outros, caracterizando aí o ramo conhecido como gramática.

Os autores refletem sobre as críticas que recaem sobre os linguistas, dizendo que eles empregam a cultura do "tudo vale" na língua. Entretanto, ao longo deste capítulo, eles vão desmistificando essa hipótese, reforçando que os linguistas não são contra a gramática normativa e a norma-padrão, eles são "(...) críticos do anacronismo e irrealismo da atual norma-padrão brasileira" (p. 91), pois o principal problema nessas discussões é saber de onde a norma-padrão deve emergir.

Por meio das considerações feitas por grandes estudiosos que atravessaram os séculos, os autores vão costurando a história das normas para que o leitor compreenda os significados que thes foram atribuídos. Começando por Quintiliano e chegando aos primeiros gramáticos portugueses Fernão de Oliveira e João de Barros.

Faraco e Zilles dizem que é impossível selecionar novas estruturas na língua sem descrever o que realmente é habitual, a fim de que as normas não recaiam sobre regras inventadas ou, como definiu Mário de Alencar, "fetiche gramatical". Para melhor elucidar isso, os autores citam o invencionismo na distinção de uso de "este" e "esse" (p. 114-115).

A norma-padrão utilizada como controle social é chamada pelos autores de norma curta, pois ela redime a língua, além de ser, infelizmente, a norma que predomina nas escolas, trazendo grandes prejuízos para o ensino. Uma alternativa para fugir dessa imposição é um estudo cada vez mais crítico sobre a norma-padrão, eliminando as regras que provêm de invenções, uma vez que as regras devem ser vistas como possibilidades e não serem impostas.

No capítulo três, os autores fazem um passeio pela história da Língua Portuguesa para explicar as normatizações. Tratam da origem de seu nome, estabelecido no século XV. Faz também uma reflexão sobre as manifestações dessa língua na história, desde a oralidade que foi durante muito tempo o modo 
como a língua se manifestava, passando para a importância dada à escrita que só ganhou destaque quando o reino de Portugal passou a ter a necessidade de construir sua parte jurídica.

Os autores destacam D. Duarte, D. Pedro e D. Henrique, filhos de D. João I, como tendo grande contribuição para as atividades culturais e linguísticas daquela época, pois eles eram intelectuais que liam, traduziam e possuíam manuscritos importantes. Os trabalhos desenvolvidos por eles acabaram contribuindo para o desenvolvimento de uma norma culta portuguesa que se baseava no "bom costume do falar".

Faraco e Zilles chamam atenção para a função do cronista-mor, que possuía como objetivo criar e registrar memórias, colaborando assim para a consolidação da norma culta portuguesa, principalmente com a expansão marítima, que fez com que se tornasse uma língua internacional.

Os autores ainda tecem comentários sobre a reforma ortográfica da língua e seus possíveis prejuízos para a escolarização e para o mercado editorial, além de traçar um histórico dos acordos firmados pelos países membros do Instituto Internacional da Língua Portuguesa, criado em 1989 no Maranhão.

Tratam ainda das primeiras gramáticas que foram utilizadas nas casas senhoriais, tendo os nobres e aristocratas como público e isso era defendido pelo gramático Jerónimo Contador de Argote, que enfatizava que o "mau português" era utilizado pelas pessoas rústicas e se encontrava em oposição aos "bem-criados". O ensino de gramática foi pensado por António José dos Reis Lobato, cuja obra Arte foi empregada por determinação nas escolas após sua consideração sobre que era preciso formar pessoas aptas a escreverem bem.

Em 1836, "(...) foi criada em Portugal uma pequena rede de liceus voltados para a chamada educação secundária (...)" (p. 150), visando as classes sociais em ascensão. Contudo, foi somente com as atividades jornalísticas e com as produções de livros que a escrita começou a ganhar novos espaços.

Diante disso, os gramáticos "(...) passaram a adotar um discurso recheado de condenações e prescrições" (p. 151). Surgiram então, no final do século XIX, os chamados consultórios gramaticais na imprensa. Cândico de Figueiredo publicou um que possuía "(...) discurso ofensivo e debochado sobre fatos da língua, que teve e, infelizmente, continua a ter seguidores, em especial no Brasil. (...) não procura entender e explicar os fatos que anota, mas se contenta em condená-los (...)" (p. 151). É a esse tipo de discurso que Faraco (2008) denominou norma curta.

Faraco e Zilles enfatizam que ainda continuamos sem respostas para saber lidar com a norma culta e a norma-padrão, principalmente no ensino. Enquanto isso, continuamos a aceitar as verdades impostas pelas autoridades gramaticais, baseadas nos modelos "puros" praticados pelos colonizadores e discriminando as variedades que não nasceram em Portugal.

No quarto e último capítulo, os autores trazem possibilidades de como pensar os conceitos de normas no contexto do ensino. Eles argumentam que as crianças aprendem a adaptar suas falas de acordo com os contextos e para quem estão falando. Assim, é muito importante que o ensino da variação linguística esteja presente nas salas de aula.

Os autores retomam alguns conceitos mencionados na obra para repensar a prática no ensino da língua, tais como o de norma-padrão, de certo-errado, de norma culta e de plenitude formal.

A partir de exemplificação, os autores mostram como trabalhar o conceito de norma culta em sala, mostrando que é preciso que os alunos aprendam que as normas podem variar ao longo dos anos, 
pois a língua está em constante mudança. Além disso, segundo os autores, os alunos irão compreender também que as variedades possuem uma gramática própria.

É preciso ainda, tendo em vista as análises dos autores, defender um ensino que mostre "(...) aos alunos como as variedades populares, rurais e urbanas, orais e letradas funcionam, em contraste com a variedade que denominamos de norma culta e, também, em contraste com a norma-padrão (...)" (p. 201). Tudo isso serve para que os alunos percebam de uma vez por todas que todo falante é capaz de adaptar suas falas aos diversos contextos sociais, revelando-se como o camaleão linguístico. 0 ensino não pode ficar engessado, pautado na norma-padrão. $\mathrm{O}$ aluno precisa ter contato com as demais variedades que se fazem presentes na sociedade, somente assim ele vai conseguir construir seu repertório linguístico e refletir sobre a língua.

Para finalizar o livro, os autores dizem que esperam que tal material tenha sido um convite ao debate crítico sobre norma-padrão, para que as pessoas possam colaborar para uma melhoria no ensino de Língua Portuguesa. Em sala de aula se faz indispensável ouvir e respeitar as vozes dos alunos, suas dúvidas, anseios, seus valores, suas culturas. Assim, as aulas serão um momento de aprendizado mútuo. Os autores concluem afirmando que o ensino deve ser menos burocrático e mais criativo. 